\title{
Methane and nitrous oxide emissions in The Netherlands: ambient measurements support the national inventories
}

\author{
S. van der Laan, R. E. M. Neubert, and H. A. J. Meijer \\ Centre for Isotope Research, University of Groningen, Groningen, The Netherlands
}

Received: 14 May 2009 - Published in Atmos. Chem. Phys. Discuss.: 11 September 2009

Revised: 19 November 2009 - Accepted: 30 November 2009 - Published: 15 December 2009

\begin{abstract}
We present net emission estimates of $\mathrm{CH}_{4}$ and $\mathrm{N}_{2} \mathrm{O}$ of The Netherlands based on measurements conducted during the period of May 2006 to April 2009 at station Lutjewad, The Netherlands $\left(6^{\circ} 21^{\prime} \mathrm{E}, 53^{\circ} 24^{\prime} \mathrm{N}, 1 \mathrm{~m}\right.$ a.s.l. $)$.

${ }^{222}$ Radon mixing ratios were applied as an indicator for vertical mixing and long-range air mass transport and used to calculate the net surface fluxes from atmospheric mixing ratios of $\mathrm{CH}_{4}$ and $\mathrm{N}_{2} \mathrm{O}$. Our study shows that our measurement site Lutjewad is well-suited to measure emissions from The Netherlands and validation of the national inventories using the ${ }^{222}$ Radon flux method. Since this study is purely observation-based it is independent from inventories or atmospheric models. Our results are compared to the national inventories as reported to the UNFCCC. We found net emissions of: $(15.2 \pm 5.3) \mathrm{t} \mathrm{km}^{-2} \mathrm{a}^{-1}$ for $\mathrm{CH}_{4}$ and $(0.9 \pm 0.3) \mathrm{t} \mathrm{km}^{-2} \mathrm{a}^{-1}$ for $\mathrm{N}_{2} \mathrm{O}$. These values are lower than the inventory-based emissions (2006-2008 averages) of $(18.3 \pm 3.3) \mathrm{t} \mathrm{km}^{-2} \mathrm{a}^{-1}$ for $\mathrm{CH}_{4}$, and $(1.3 \pm 0.6) \mathrm{t} \mathrm{km}^{-2} \mathrm{a}^{-1}$ for $\mathrm{N}_{2} \mathrm{O}$, but the differences are insignificant.
\end{abstract}

\section{Introduction}

In the face of the recent and predicted climate changes, most nations joined an international treaty: the United Nations Framework Convention on Climate Change (UNFCCC). The goal of this treaty is to reduce global warming and to determine measures for adaptation to temperature increases which are inevitable. Of major concern to the UNFCCC is the rapid increase of the long-lived greenhouse gases (LLGHGs) carbon dioxide $\left(\mathrm{CO}_{2}\right)$, methane $\left(\mathrm{CH}_{4}\right)$, nitrous oxide $\left(\mathrm{N}_{2} \mathrm{O}\right)$ and halocarbons (a group of gases containing fluorine, chlorine and bromine). Their radiative forcing (RF) in

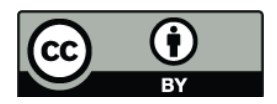

Correspondence to: S. van der Laan (s.van.der.laan@rug.nl)
2005 as compared to pre-industrial times was estimated to be respectively: $(1.66 \pm 0.17) \mathrm{W} \mathrm{m}^{-2},(0.48 \pm 0.05) \mathrm{W} \mathrm{m}^{-2}$, $(0.16 \pm 0.02) \mathrm{W} \mathrm{m}^{-2}$ and $(0.34 \pm 0.03) \mathrm{W} \mathrm{m}^{-2}$ (Forster et al., 2007). These gases are significantly contributing to the total positive RF contributions of around $3.2 \mathrm{~W} \mathrm{~m}^{-2}$.

In order to quantify the major sources of the GHGs, to monitor the national emissions and verify the effects of national reduction policies, UNFCCC partners commit themselves to annually report their greenhouse gas emissions. These reports are based on estimations of the amount of GHG sources (e.g. traffic, agriculture) and sinks (e.g. forest growth) and the amount of greenhouse gases they produce or take up (emission factors) when active. This method is therefore highly dependent on the accuracy and completeness of the emission data. Inventories strongly rely on statistics of for example cattle, traffic and energy consumption of factories which are usually provided by the individual sources. On top of that assumptions are needed concerning the amount of greenhouse gases an individual source emits when active: the applied emission factors which most likely contain (systematic) errors. In order to cope with the uncertainties related to the inventory method, parties are encouraged by the UNFCCC to develop and implement an independent validation system based on atmospheric measurements.

Our study focuses on estimating the net surface emissions of $\mathrm{CH}_{4}$ and $\mathrm{N}_{2} \mathrm{O}$ in The Netherlands from ambient mixing ratios of $\mathrm{CH}_{4}, \mathrm{~N}_{2} \mathrm{O}$ and ${ }^{222}$ Radon $\left({ }^{222} \mathrm{Rn}\right)$, to provide such an independent validation of the national inventories. Furthermore, we are interested if we can also estimate the surface emissions of the neighbouring countries Germany and Belgium.

In order to determine surface emissions of $\mathrm{CH}_{4}$ and $\mathrm{N}_{2} \mathrm{O}$ from their ambient mixing ratios ${ }^{222} \mathrm{Rn}$ is used as a reference tracer for atmospheric mixing and transport (Levin, 1984; Thom et al., 1993; Schmidt et al., 1996). ${ }^{222} \mathrm{Rn}$ is a radioactive noble gas (its radioactive half-life is 3.825 days) which is produced at a constant rate from ${ }^{226}$ Radium which

Published by Copernicus Publications on behalf of the European Geosciences Union. 
is relatively uniformly distributed in all soils. When released to the atmosphere, ${ }^{222} \mathrm{Rn}$ experiences the same atmospheric circumstances (transport and mixing) as any other constituent. Hence, when the surface emanation of ${ }^{222} \mathrm{Rn}$ is known, the surface emission of a certain constituent can be determined from the changes in mixing ratios of this constituent and ${ }^{222} \mathrm{Rn}$. Using ${ }^{222} \mathrm{Rn}$ to determine surface fluxes from mixing ratios has already been successfully applied in other studies e.g. to: $\mathrm{CO}_{2}$ (Levin, 1987; Gaudry et al., 1990; Schmidt et al., 2003), $\mathrm{N}_{2} \mathrm{O}$ (Schmidt et al., 2001; Wilson et al., 1997), $\mathrm{CH}_{4}$ (Thom et al., 1993; Schmidt et al., 1996; Levin et al., 1999), CFCs (Biraud et al., 2002), peroxyacetyl nitrate (Schrimpf et al., 1996) and $\mathrm{NO}$ and $\mathrm{NO}_{2}$ (Rohrer et al., 1998). New aspects of our study are related to the aimedat catchment area of the emissions (in our case we focus mainly on The Netherlands), and our data selection method. The latter aims at locating individual sources or source areas instead of analyses of daily, weekly or monthly averaged data. We further propose a small improvement in the ${ }^{222} \mathrm{Rn}$ decay correction when dealing with emissions from large distances. Also, we apply data from a newly available European ${ }^{222} \mathrm{Rn}$ soil emission map based on a network of gamma dose rate measurements (Szegvary, 2007). To account for the fact that the net emissions are positive (i.e. from surface to atmosphere) and the method is highly sensitive to nearby emissions we use a lognormal regression fit to estimate the annual surface emissions of $\mathrm{CH}_{4}$ and $\mathrm{N}_{2} \mathrm{O}$.

Our results are based on semi-continuous measurements of ambient mixing ratios of $\mathrm{CH}_{4}, \mathrm{~N}_{2} \mathrm{O}$ and ${ }^{222} \mathrm{Rn}$ which were performed at our atmospheric measurement station Lutjewad during the period May 2006 to March 2009. The applied instrumentation is described in Sect. 2. In Sect. 3 the data selection routine and the method for the calculation of the surface fluxes is described. Finally, in Sect. 4 our purely observation-based results are compared to the emission inventories of The Netherlands and its surrounding countries as reported to the UNFCCC.

\section{Measurement site Lutjewad and applied instrumen- tation}

\subsection{Site description}

Station Lutjewad is situated on the Dutch North Sea coast (see Fig. 1) at $53^{\circ} 24^{\prime} 18^{\prime \prime} \mathrm{N}, 6^{\circ} 21^{\prime} 13^{\prime \prime} \mathrm{E}, 1 \mathrm{~m}$ a.s.l. The station is about $30 \mathrm{~km}$ to the Northwest of the city of Groningen. The station is equipped with a $60 \mathrm{~m}$ tall tower which has air intakes at the top, from where ambient air is continuously flushed down to a laboratory where the analyses take place. The tower is equipped with basic meteorological equipment, measuring air temperature, humidity, atmospheric pressure, wind-speed and -direction and solar radiation. As the station is normally unmanned, all equipment is designed to operate

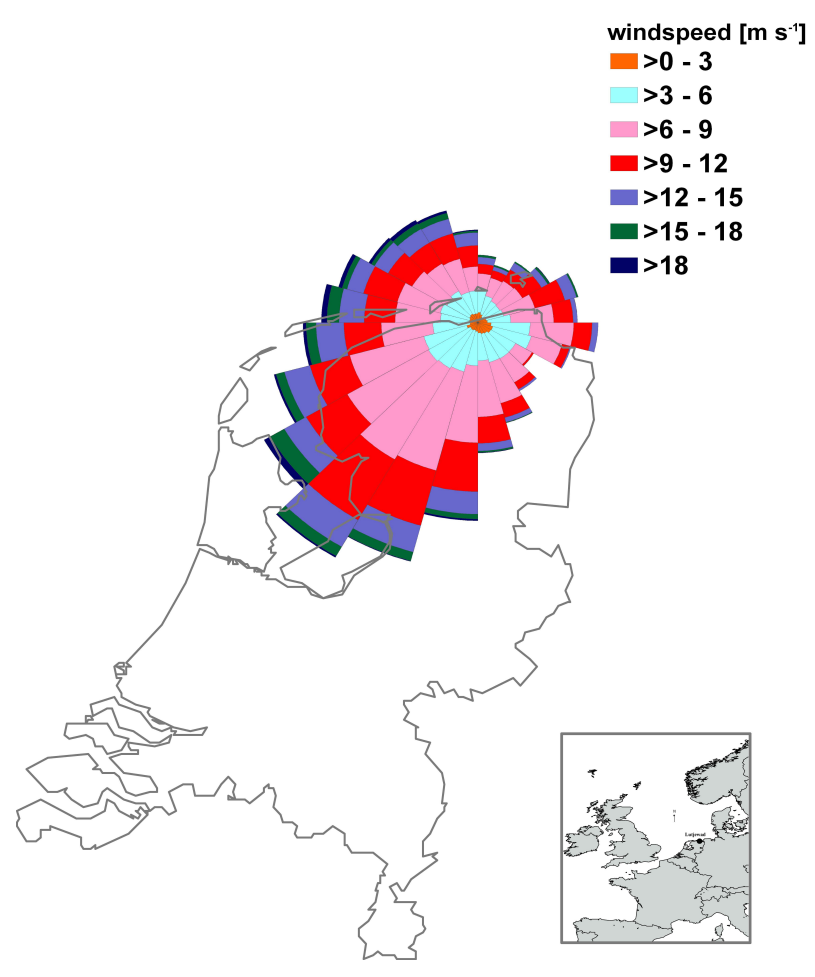

Fig. 1. Wind conditions at station Lutjewad (measured at $60 \mathrm{~m}$ ) for the period of May 2006 to April 2009 (map produced under creative commons license by Planiglobe.com). Bin size is 15 degrees and the north is pointing up. The prevailing wind direction, about $31 \%$ of all time, is between $195^{\circ}$ and $255^{\circ}$. Most abundant wind speeds are found between $6 \mathrm{~m} \mathrm{~s}^{-1}$ and $9 \mathrm{~m} \mathrm{~s}^{-1}$. About $35 \%$ of all wind speeds were found in this range.

fully automated and data are sent on a daily basis to our institute in Groningen (Van der Laan et al., 2009).

Wind direction at the site is mostly southwest and west (Fig. 1). With northerly winds, the sampled air can be characterized as having background mixing ratios. With wind directions between approx. $40^{\circ}-240^{\circ}$ air masses with continental contributions are sampled. During the period between May 2006 and April 2009 the prevailing wind direction (31\% of all data) was between $195^{\circ}$ and $255^{\circ}$. Wind speeds between 6 and $9 \mathrm{~m} / \mathrm{s}$ (at $60 \mathrm{~m}$ above the ground) were found to be the most abundant ( $35 \%$ of all data) in this period.

\subsection{Atmospheric $\mathrm{CH}_{4}$ and $\mathrm{N}_{2} \mathrm{O}$ measurements}

Ambient air is continuously collected from an air intake at $60 \mathrm{~m}$ height and immediately dried (up to $50 \%$ reduction in humidity) using a Nafion membrane drier (MD 11072-S, Perma Pure, Toms River, New Jersey). The predried air is subsequently pumped down through polyethylene/aluminium tubing (1/2" O.D., Synflex 1300, Eaton, Gembloux, Belgium) to the laboratory where analyses by a modified Agilent HP 6890N Gas Chromatograph (GC) take place. The total travel time from the inlet to the GC is about 
3 minutes. After cryogenic cooling to a dew point of $-50^{\circ} \mathrm{C}$ (Neubert et al., 2004), the sample air is fed into the $\mathrm{GC}$ where separation and analyses of $\mathrm{CH}_{4}$ and $\mathrm{N}_{2} \mathrm{O}$ (and also $\mathrm{CO}_{2}, \mathrm{CO}$ and $\mathrm{SF}_{6}$ ) take place (Van der Laan et al., 2009). $\mathrm{CH}_{4}$ is separated using a 10 feet Haysep Q packed column (3/16 inch, mesh 80/100) and analyzed with a Flame Ionization Detector (FID). $\mathrm{N}_{2} \mathrm{O}$ is separated using a 4 feet Haysep Q packed pre-column (3/16 inch, mesh 80/100) and a 6 feet Haysep Q packed analytical column (3/16 inch, mesh 80/100) before being analyzed with a micro Electron Capture Detector ( $\mu \mathrm{ECD})$. The pre-column is used to prevent any unwanted substances (e.g. $\mathrm{CO}_{2}$ ) from entering the $\mu \mathrm{ECD}$. One complete run (measuring $\mathrm{CH}_{4}$ and $\mathrm{N}_{2} \mathrm{O}$ simultaneously) takes about $6.5 \mathrm{~min}$. At least three times per day, a sample measurement is substituted by a target cylinder for the purpose of quality control. Typical measurement uncertainty is about $0.3 \mathrm{ppb}$ for $\mathrm{N}_{2} \mathrm{O}$ and $0.8 \mathrm{ppb}$ for $\mathrm{CH}_{4}$.

\subsection{Atmospheric ${ }^{222}$ Radon measurements}

${ }^{222}$ Radon mixing ratios are semi-continuously measured (integrated over $30 \mathrm{~min}$ ) with an ANSTO dual-flow loop twofilter detector (Whittlestone and Zahorowski, 1998). During the travel from the inlet (about $15 \mathrm{~min}$ ) to the detector, all ${ }^{220} \mathrm{Rn}$ atoms will already be decayed (its half-life time is 55.6 s) and they do therefore not influence the ${ }^{222} \mathrm{Rn}$ results. Any (radioactive) decay products and aerosols are filtered out before the sample air enters the detector. The air is then led to a 15001 delay chamber, the ${ }^{222} \mathrm{Rn}$ decay products are sampled on a second filter and their decays are detected by a photomultiplier and counted per half hour interval. The total uncertainty of the measurements is based upon the number of decay counts and the uncertainty of the ${ }^{222} \mathrm{Rn}$ source which is used to calibrate the device, and is typically $5 \%$.

\section{Methodological description}

\subsection{Estimation of surface emissions from ambient mix- ing ratios}

We derive the surface emission rates of $\mathrm{CH}_{4}$ and $\mathrm{N}_{2} \mathrm{O}$ from their ambient mixing ratios by using ${ }^{222} \mathrm{Rn}$ as a reference tracer for atmospheric mixing and transport (Levin, 1984; Thom et al., 1993; Schmidt et al., 1996). ${ }^{222} \mathrm{Rn}$ is a radioactive noble gas (its radioactive half life is 3.825 days) which is produced at a constant rate by the decay of ${ }^{226}$ Radium, which is present in all soils and is relatively uniformly distributed. Via the soil air, radon is emitted into the atmosphere where it is only subjected to radioactive decay and dilution by atmospheric transport (e.g. mixing with the free troposphere under unstable atmospheric conditions). With knowledge of the transit time, the ${ }^{222} \mathrm{Rn}$ in a given air mass can, theoretically, be corrected for radioactive decay, transforming ${ }^{222} \mathrm{Rn}$ to an ideal conservative tracer. Since the dilution by atmospheric mixing is the same for ${ }^{222} \mathrm{Rn}$ as for any other tracer, in our case $\mathrm{CH}_{4}$ and $\mathrm{N}_{2} \mathrm{O}$, the surface emissions of $\mathrm{CH}_{4}$ and $\mathrm{N}_{2} \mathrm{O}$ can be determined from their mixing ratios and the mixing ratio of ${ }^{222} \mathrm{Rn}$, provided the original ${ }^{222} \mathrm{Rn}$ soil flux is known, remains constant and is homogenous for the spatial and temporal scale of influence. The surface flux of a given tracer $\mathrm{x}$ is then given by:

$\bar{\Phi}_{x}=\bar{\Phi}_{R n} \cdot \frac{\Delta C_{x}}{\Delta C_{R n}}$

Herein $\phi_{\mathrm{X}}$ represents the estimated surface flux of a tracer $\mathrm{x}, \phi_{R n}$ is the ${ }^{222} \mathrm{Rn}$ soil flux rate, $\mathrm{C}_{\mathrm{x}}$ is the atmospheric mixing ratio of a tracer $\mathrm{x}$ and $\mathrm{C}_{R n}$ is the atmospheric mixing ratio of ${ }^{222}$ Radon. The $\Delta$ 's represent departures from their background values. The over-bars represent the means for the spatial and temporal scales of influence. One of the main underlying assumptions of the ${ }^{222} \mathrm{Rn}$ flux method is that both the surface emissions of ${ }^{222} \mathrm{Rn}$ and the tracer of interest are homogeneously spread over the area that is influencing the measurements (catchment area). This, however, is not always the case. For example, $\mathrm{CH}_{4}$ can be emitted at a certain moment from a point source and then transported to our mast. During this travel there will be a continuous addition of ${ }^{222} \mathrm{Rn}$ from the surface (the magnitude of this addition will depend on the soil type of the surface) but not of $\mathrm{CH}_{4}$. Thus, the method is less suited for the detection and strength analysis of individual point sources and more uncertain for catchment areas which are very heterogeneous.

\subsection{Data selection and analyses}

When a significant departure of ${ }^{222} \mathrm{Rn}$ from the background mixing ratio is observed for at least four consecutive hours, we define this as the start of an event. During an event ${ }^{222} \mathrm{Rn}$ as well as other tracers (e.g. surface emissions of $\mathrm{CH}_{4}$ or $\mathrm{N}_{2} \mathrm{O}$ ) are trapped in the atmospheric boundary layer. An event terminates when the wind direction changes or vertical mixing is re-established. With vertical mixing sustaining for a sufficiently long time the mixing ratios are reset to background conditions. Occasionally, vertical mixing is too weak and a new rise of ${ }^{222} \mathrm{Rn}$ starts already before mixing ratios have been fully restored to background levels.

An example of a few events (indicated with shaded areas) as observed at our station in November 2007 is shown in Fig. 2. The first event on the left, indicated with the number 1 , shows a good correlation between the ambient mixing ratios of ${ }^{222} \mathrm{Rn}, \mathrm{CH}_{4}$ and $\mathrm{N}_{2} \mathrm{O}$. Starting from marine baseline levels, with the wind coming from the North Sea, they rapidly increase simultaneously at about 5:30 LT in the morning. By this time, the wind direction has changed to south-southwest and wind speed gradually increases from about $5.5 \mathrm{~m} \mathrm{~s}^{-1}$ to $8.5 \mathrm{~m} \mathrm{~s}^{-1}$. At about 18:30 LT the wind very rapidly changes to the direction of the North Sea again thereby terminating the event.

The events do not necessarily start at marine baseline levels. A very slow increase of ${ }^{222} \mathrm{Rn}$ is sometimes observed 


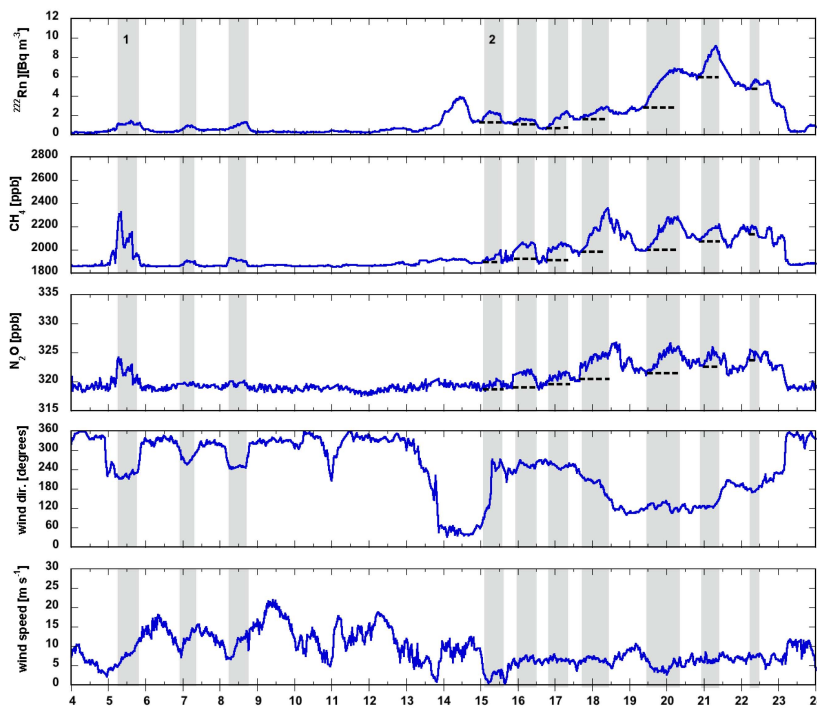

Fig. 2. Example of the different types of events (shaded areas) observed at station Lutjewad. The left part of the figure shows three typical short-range events (the first indicated with 1) where the increase of ${ }^{222} \mathrm{Rn}$ mixing ratios start from baseline levels. The events starting from an event which is marked with a 2 are built up on a slow increase in the ${ }^{222} \mathrm{Rn}$ mixing ratio which indicates a persistent continental influence. These events are treated as short-range events after a new baseline is defined (dotted lines) for each individual event.

which can increase steadily over several days, indicating a long continental influence. This can be seen in the right part of Fig. 2. When regional atmospheric conditions are such that a new event is formed, these events are assumed to be influenced mostly by regional surface emissions. In Fig. 2 the first of such an event is indicated with a 2. However, in order to be representative for short-range surface fluxes we have to take into account their new baseline. Therefore we subtract from these peaks the starting value (of the mixing ratios) for each individual peak. In Fig. 2 we illustrated this with the dashed lines.

For how long an air mass has been travelling from the emission's source(s) will depend on the meteorological circumstances (i.e. wind speed or changing wind direction). But, provided these circumstances remain stable, we can assume this transit time is the same for the whole air mass which is collected during an event. Therefore we assume the length of an event can be used as an indicator for the area of influence. For example, since the first event in Fig. 2 has a total duration of about $13 \mathrm{~h}$ and the average wind speed is about $7 \mathrm{~m} \mathrm{~s}^{-1}$, we estimate that the maximum distance of influence is about $330 \mathrm{~km}$ from our station which, in this direction, is just outside the Dutch border. Therefore, we will classify this event, as well as the following two (smaller) events, as a short-range event and assume it is mainly influenced by surface emissions from The Netherlands. The following event

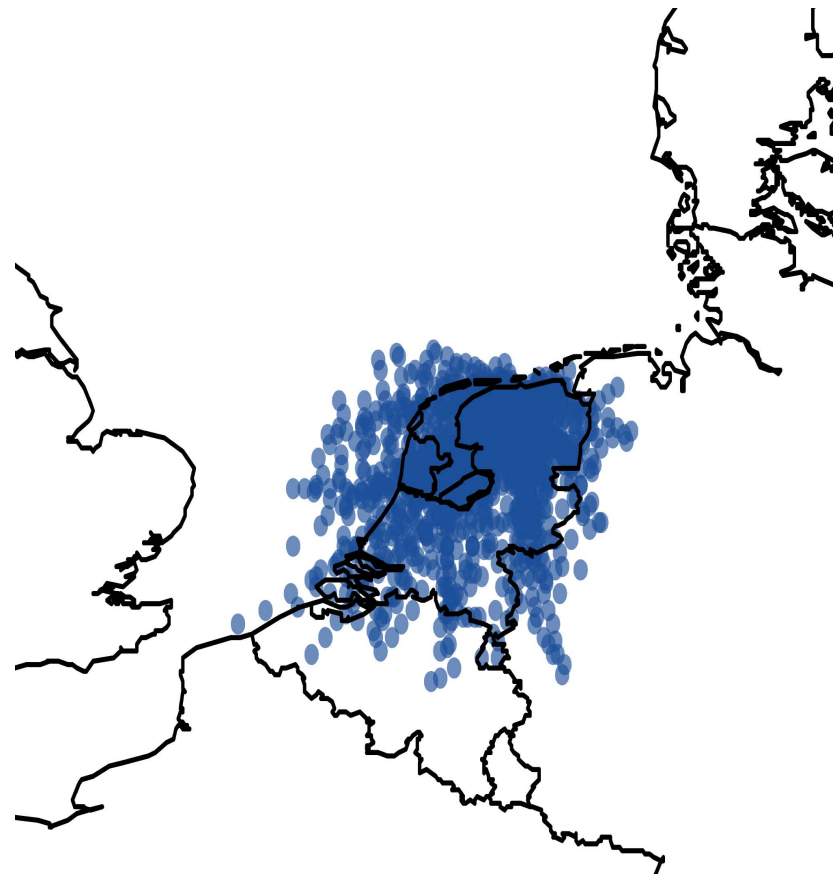

Fig. 3. Back trajectories for the short range events including the superimposed events. The dots represent hourly points on the trajectory. These events were considered to be mainly influenced by emissions from The Netherlands and selected for further analyses.

was not selected because the wind direction indicated a nonDutch origin of these air masses. In our quest, to select only events which are influenced mainly by Dutch surface emissions (and not from the near surroundings of our tower or abroad), we selected only events which endured at least $4 \mathrm{~h}$ and at most $17 \mathrm{~h}$. Then, back trajectories were made of all events using the Hysplit 4 lagrangian back trajectory model (Draxler and Rolph, 2003). For each individual event, back trajectories were calculated corresponding to the total duration of the event, i.e. if an event sustained for $8 \mathrm{~h}$, we calculated its trajectory $8 \mathrm{~h}$ back in time. As the starting point of the back trajectory we used the last data point of an event (before vertical mixing was re-established). Back trajectories starting in the middle of an event were also made in order to validate steady state conditions during travel. In this way we tried to estimate the main area influencing the measurements during the course of an event. Events were only accepted for further analyses if the trajectories indicated that the track of the air mass was mainly (approx. $>70 \%$ ) over The Netherlands and thereby suggesting that these events were dominantly influenced by Dutch emissions. Figure 3 shows hourly points on the trajectories of the events which were selected for further analysis.

A linear least square regression fit between the half hourly averaged observations of $\mathrm{CH}_{4}$ and ${ }^{222} \mathrm{Rn}$, and $\mathrm{N}_{2} \mathrm{O}$ and ${ }^{222} \mathrm{Rn}$ is made for each individual event. An example is shown in Fig. 4a and b for an event starting on 18 August 2006 

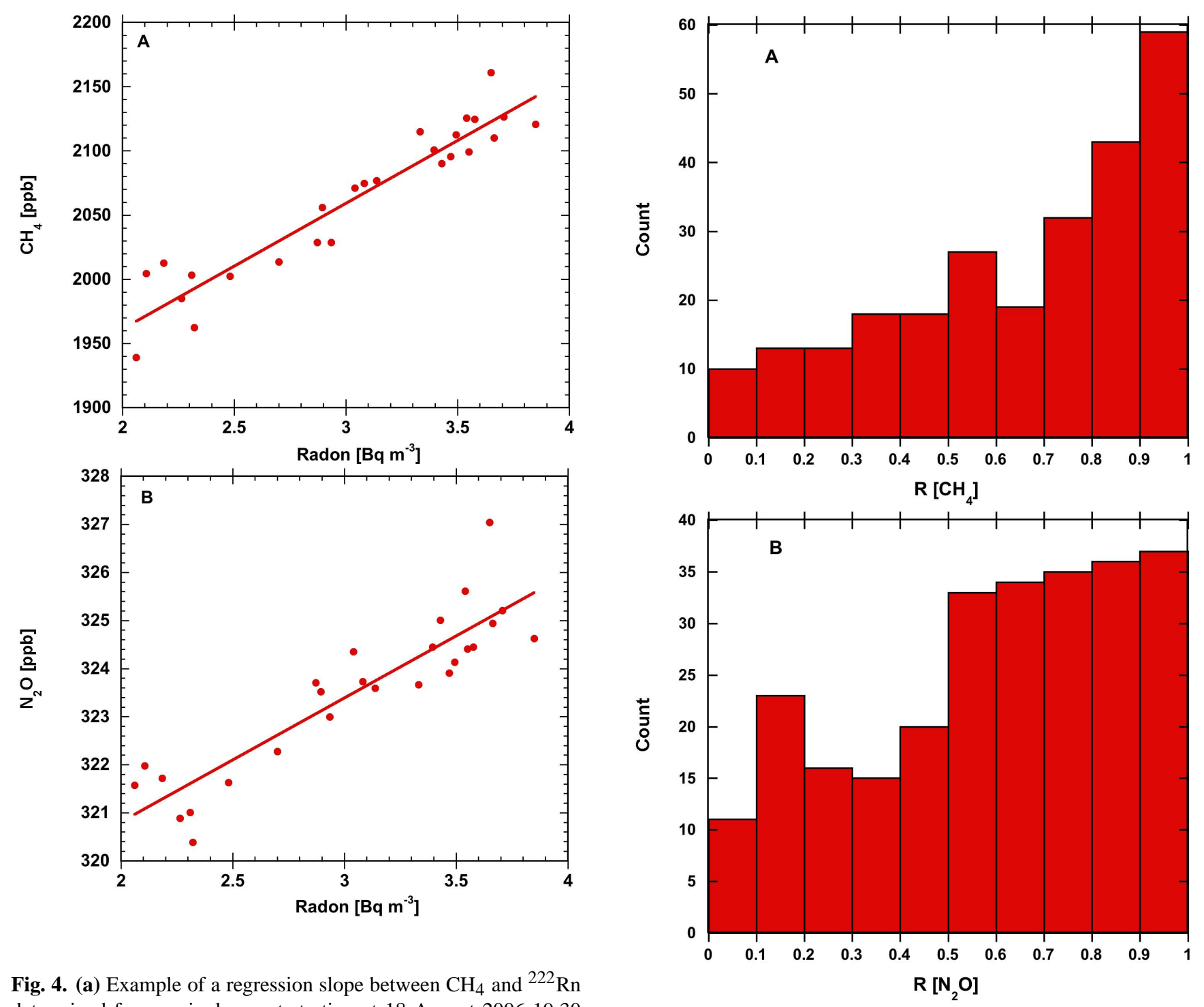

Fig. 4. (a) Example of a regression slope between $\mathrm{CH}_{4}$ and ${ }^{222} \mathrm{Rn}$ determined from a single event starting at 18 August 2006 19:30 LT and ending at 08:00 LT the next day. ${ }^{222} \mathrm{Rn}$ increased by about $2 \mathrm{~Bq} \mathrm{~m}^{-3}$ during this period and $\mathrm{CH}_{4}$ by about $170 \mathrm{ppb}$. (b) Similar to (a) but now for $\mathrm{N}_{2} \mathrm{O}$ which increased by about $4.5 \mathrm{ppb}$ in the same time.

19:30 LT and ending at 08:00 LT the next day. During the event the mixing ratio of ${ }^{222} \mathrm{Rn}$ increased by about $2 \mathrm{~Bq} \mathrm{~m}^{-3}$ during this period and $\mathrm{CH}_{4}$ by about $170 \mathrm{ppb}$. In the same time the mixing ratio of $\mathrm{N}_{2} \mathrm{O}$ increased by about $4.5 \mathrm{ppb}$. For both regression slopes a high correlation was found between ${ }^{222} \mathrm{Rn}$ and the other tracer.

Making linear regression fits for each individual event, instead of for example weekly or monthly averaged data, enables us not only to estimate the source areas (and thus filter out events which are highly influenced by emissions from abroad) but also gives a higher temporal resolution. However, with so few data points (typically in the order of about 15-25) the fits can only be used if a high correlation between

the two mixing ratios is found. A high correlation factor is not always expected since $\mathrm{CH}_{4}$ and especially $\mathrm{N}_{2} \mathrm{O}$ can also originate from temporary point sources. The regression fits were evaluated by making histograms of their regression coefficients, see Fig. 5. We decided to use a minimal correlation coefficient of $R=0.7$ as a limit for further analyses in order to maintain regression slopes with a sufficient correlation (the method assumes a correlation between ${ }^{222} \mathrm{Rn}$ and $\mathrm{CH}_{4} / \mathrm{N}_{2} \mathrm{O}$ ) and still maintain enough events to determine annual averages.

Additional to all events which are assumed to represent the national emissions, we obtained a so-called long-range dataset. This dataset contains events which are believed not 
to represent emissions from The Netherlands (i.e. those used in the short range analysis), as well as well-mixed background mixing ratios and slow increases over several days from this background. From this dataset we excluded all data with wind directions from $280^{\circ}-40^{\circ}$ (marine sector) and determined the regressions slopes from monthly binned mixing ratios.

In order to estimate annual emissions from the individual fluxes usually a median (Rohrer et al., 1998) or (monthly) mean (Levin, 1987; Gaudry et al., 1990; Thom et al., 1993; Schmidt et al., 1996, 2001, 2003; Schrimpf et al., 1996; Wilson et al., 1997; Levy et al., 1999; Biraud et al., 2000; Messager et al., 2008) is used. However, since the ambient measurements are very sensitive for nearby point source emissions, annual emission estimates using a median or a (Gaussian) mean would probably be overestimated. Therefore, we decided to use a lognormal distribution which is less sensitive for very high values and thus less sensitive for the nearby sources. A lognormal distribution is furthermore reasonable since the emissions are directed from the surface to the atmosphere and are therefore positive in sign.

\subsection{Correction for radioactive decay of ${ }^{222}$ Radon}

The measured mixing ratios of (e.g.) $\mathrm{CH}_{4}$ and ${ }^{222} \mathrm{Rn}$ during an event are influenced by the same conditions (i.e. vertical mixing, dilution) but additionally the mixing ratios of ${ }^{222} \mathrm{Rn}$ have been subject to radioactive decay: $A_{t}=A_{0} \cdot e^{-\lambda \tau}$, wherein $A_{t}$ represents the activity or mixing ratio of ${ }^{222} \mathrm{Rn}$ at a given time $\mathrm{t}, A_{0}$ is the original ${ }^{222} \mathrm{Rn}$ activity, $\tau$ is the transit time of the air mass and $\lambda$ is the decay constant $\left(0.182 \mathrm{~d}^{-1}\right)$ of ${ }^{222} \mathrm{Rn}$. The measured ${ }^{222} \mathrm{Rn}$ mixing ratio can be corrected for this decay by multiplying the measured ${ }^{222} \mathrm{Rn}$ mixing ratios individually with $e^{\lambda \tau}$ when the transit time is known. In practice, the exact transit time and ${ }^{222} \mathrm{Rn}$ soil emission is usually not well-known. As a best estimate an average decay correction can be applied based on the average decay of the radon for the whole event and assuming a constant and homogeneously spread ${ }^{222} \mathrm{Rn}$ soil emission. Usually, Eq. (1) is therefore multiplied with $e^{-\lambda \tau}$, with $\tau$ being an estimated average transit time (Wilson et al., 1997; Gaudry et al., 1990; Schmidt et al., 2001; Schmidt et al., 2003) or based upon the total estimated transit time of ${ }^{222} \mathrm{Rn}$ above sea only (Biraud et al., 2000; Messager et al., 2008). The latter leads to an insufficient correction since ${ }^{222} \mathrm{Rn}$ also decays over land.

The main issue when correcting for decay lies in the estimation of the transit time of an air mass. When multiplying Eq. (1) with $e^{-\lambda \tau}$ for example, we must be aware not to use the total time of duration of an event for $\tau$ since all emissions from $\tau=0$ to $\tau<\tau_{\max }$ will then be overcorrected resulting in an underestimation of the total $\mathrm{CH}_{4}$ and $\mathrm{N}_{2} \mathrm{O}$ surface emissions. If one uses $\tau_{\max } / 2$ as an estimate for the average transit time for a given event, the error is minor but still this is principally incorrect as the radioactive decay does not follow a linear function.
Although the total transit time of an air mass from the emission's source to our site is not well known, this transit time is the same for all air masses which are collected during the course of an event, assuming the atmospheric conditions do not alter significantly during the event. The emissions of $\mathrm{CH}_{4}$ and $\mathrm{N}_{2} \mathrm{O}$ can then be calculated by multiplying Eq. (1) with:

$$
\frac{\int_{0}^{\tau_{\max }} e^{-\lambda \cdot \tau} d \tau}{\tau_{\max }}=\frac{-\lambda^{-1}\left(e^{-\lambda \cdot \tau_{\max }}-1\right)}{\tau_{\max }}=\frac{1-e^{-\lambda \cdot \tau_{\max }}}{\lambda \cdot \tau_{\max }}
$$

which is the average decay correction for the whole air mass.

For $\tau_{\max }=5$ days the difference between (2) and a simple $e^{-(1 / 2) \lambda \cdot \tau_{\max }}$ correction is about $5 \%$.

\section{$3.4 \quad{ }^{222}$ Rn soil flux estimations}

For the ${ }^{222} \mathrm{Rn}$ soil flux of The Netherlands we used an average value of $0.29 \pm 0.10$ atoms $\mathrm{cm}^{-2} \mathrm{~s}^{-1}$ as calculated by Szegvary (2007). These authors have created a European ${ }^{222} \mathrm{Rn}$ soil flux map based on the correlation of ${ }^{222} \mathrm{Rn}$ and gamma-dose rate measurements which were performed in 2006. Using this method they were able to use data from a high-density radiation monitoring network improving spatial data coverage. A large part of The Netherlands are coastal areas (North Sea in the west and the Wadden Sea in the North) and also there are many river deltas. Since these areas have a high moisture content the ${ }^{222} \mathrm{Rn}$ soil flux is lower in these parts compared to the parts in the south and the east of the country where the soil is more sandy and the groundwater table is lower. Szegvary (2007) found a spatial variation of \pm 0.10 atom $\mathrm{cm}^{-2} \mathrm{~s}^{-1}$ for The Netherlands. Since the ${ }^{222} \mathrm{Rn}$ soil flux is dependent on for example soil moisture, a temporal variation is expected in northern latitudes. However, below $55^{\circ} \mathrm{N}$ weekly averages were found to deviate less then $15 \%$ from the annual mean with no clear seasonal pattern (Szegvary, 2007).

For the events which were classified as long-range events an average soil flux of $(0.59 \pm 0.27)$ atoms cm $\mathrm{cm}^{-2} \mathrm{~s}^{-1}$ was assumed which is the average of Belgium $(0.65 \pm 0.14)$ atoms cm ${ }^{-2} \mathrm{~s}^{-1}$ and Germany $(0.52 \pm 0.23)$ atoms $\mathrm{cm}^{-2} \mathrm{~s}^{-1}$ as calcuated by Szegvary (2007).

\section{Results}

\subsection{Short-range events}

\subsection{1 $\mathrm{CH}_{4}$ emissions}

In total 135 events passed our selection criteria and these are thus assumed to represent the emissions from The Netherlands from May 2006 to April 2009. The typical duration of an event was around $10 \mathrm{~h}$. The results for the short range 
Table 1. Comparison between the results from the radon flux method (May 2006 to April 2009) and the national inventories (averages of 2006 and 2007) of the Netherlands. The uncertainties in the measurements are the standard uncertainty and the uncertainty in the lognormal fit. The total combined uncertainty is based on the uncertainty of the ${ }^{222} \mathrm{Rn}$ soil flux, the errors in the regression fits of the individual fluxes and the accuracy and precision of the ${ }^{222} \mathrm{Rn}, \mathrm{CH}_{4}$ and $\mathrm{N}_{2} \mathrm{O}$ measurements.

\begin{tabular}{|c|c|c|c|c|c|c|}
\hline & \multicolumn{3}{|c|}{ National inventories } & \multicolumn{3}{|c|}{ Radon flux method } \\
\hline & $\begin{array}{l}\text { The Nether- } \\
\text { lands } \\
\text { 2006-2007 }\end{array}$ & $\begin{array}{l}\text { Belgium } \\
2006\end{array}$ & $\begin{array}{l}\text { Germany } \\
2006\end{array}$ & $\begin{array}{l}\text { Median } \\
\text { (combined uncer- } \\
\text { tainty) }\end{array}$ & Lognormal fit & $\begin{array}{l}\text { Lognormal fit } \\
\text { (combined uncer- } \\
\text { tainty) }\end{array}$ \\
\hline $\begin{array}{l}\mathrm{CH}_{4} \text { short-range } \\
{\left[\mathrm{t} \mathrm{km}^{-2} \mathrm{a}^{-1}\right]}\end{array}$ & $18.3 \pm 3.3$ & & & $19.1 \pm 6.7$ & $15.2 \pm 0.4$ & $15.2 \pm 5.3$ \\
\hline $\begin{array}{l}\mathrm{N}_{2} \mathrm{O} \text { short-range } \\
{\left[\cdot 10^{-1} \mathrm{t} \mathrm{km}^{-2} \mathrm{a}^{-1}\right]}\end{array}$ & $12.6 \pm 5.7$ & & & $12.1 \pm 4.2$ & $9.2 \pm 0.3$ & $9.2 \pm 3.2$ \\
\hline $\begin{array}{l}\mathrm{CH}_{4} \text { long-range } \\
{\left[\mathrm{t} \mathrm{km}^{-2} \mathrm{a}^{-1}\right]}\end{array}$ & & 11.0 & 5.8 & $11.3 \pm 4.0$ & $8.9 \pm 0.3$ & $8.9 \pm 3.1$ \\
\hline $\begin{array}{l}\mathrm{N}_{2} \mathrm{O} \text { long-range } \\
{\left[\cdot 10^{-1} \mathrm{t} \mathrm{km}^{-2} \mathrm{a}^{-1}\right]}\end{array}$ & & 8.8 & 5.4 & $5.7 \pm 2.0$ & $4.2 \pm 0.3$ & $4.2 \pm 1.5$ \\
\hline
\end{tabular}

fluxes of $\mathrm{CH}_{4}$ are shown in Fig. 6a. Most of the events are observed in the summer. This is expected since in winter the atmosphere can be stable for longer periods and long range events are more abundant. The dataset is therefore biased towards summertime $\mathrm{CH}_{4}$ fluxes. The emissions are subject to a large variability, but no clear seasonality is observed. The emissions were corrected for ${ }^{222} \mathrm{Rn}$ decay by about $4 \%$ (on average).

As explained in Sect. 3.2 we use a lognormal distribution to estimate the annual emissions, see Fig. 6b. The lognormal distribution fits the observations very well and we find annual $\mathrm{CH}_{4}$ emissions for The Netherlands of $(15.2 \pm 0.4) \mathrm{t} \mathrm{km}^{-2} \mathrm{a}^{-1}$. This is $17 \%$ less than the $(18.3 \pm 3.3) \mathrm{t} \mathrm{km}^{-2} \mathrm{a}^{-1}$ given by the national inventories. Our uncertainties are the standard uncertainties of the regression fit, not the total combined uncertainty in the annual estimation, this will be discussed later. The value of $18.3 \mathrm{t} \mathrm{km}^{-2} \mathrm{a}^{-1}$ is the average value for 2006 and 2007 as given in the national reports. At the time of writing no estimate for 2008 was available. For comparison with previous studies we also give the results for the median and a Gaussian distribution fit. The median of the $\mathrm{CH}_{4}$ emissions is $19.1 \mathrm{t} \mathrm{km}^{-2} \mathrm{a}^{-1}$ and the mean of the monthly $\mathrm{CH}_{4}$ averages is $(22.7 \pm 1.6) \mathrm{t} \mathrm{km}^{-2} \mathrm{a}^{-1}$, the latter being heavily influenced by the few very high fluxes. All final results are given in Table 1.

\subsection{2 $\mathrm{N}_{2} \mathrm{O}$ emissions}

The fluxes of $\mathrm{N}_{2} \mathrm{O}$ for the period of May 2006 to April 2009 are shown in Fig. 7a. In total 111 events passed our selection criteria and similar to $\mathrm{CH}_{4}$, most of them occurred in the summer period. The largest fluxes appear to occur in the summer. The same correction for ${ }^{222} \mathrm{Rn}$ decay was applied to the emissions of about $4 \%$ on average. Using the lognor-

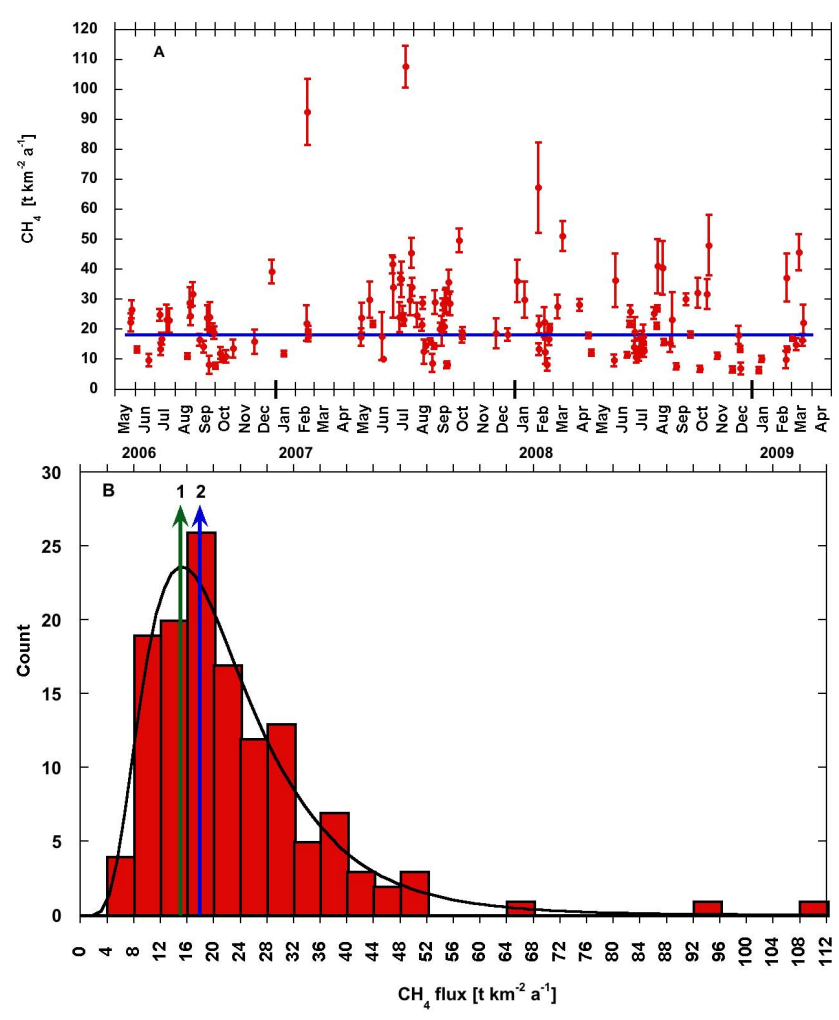

Fig. 6. (a) Fluxes of $\mathrm{CH}_{4}$ representative for emissions from the Netherlands. The error bars represent the $\pm 1 \sigma$ uncertainties of the linear regression fits of the individual slopes. The value of the national inventories is indicated by the straight line. (b) Histogram of the $\mathrm{CH}_{4}$ fluxes with a lognormal fit. Fit quality is excellent $(R=0.98)$. The arrows represent the values found using the lognormal approach (1) and the national inventory (2). 


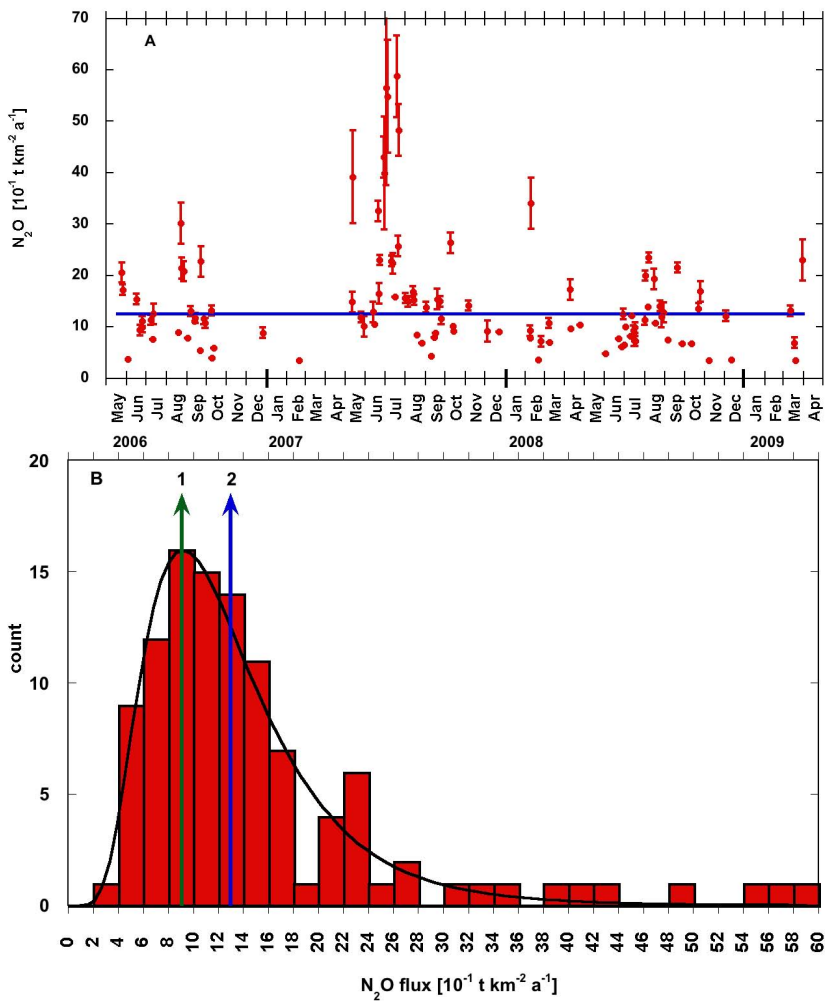

Fig. 7. (a) Fluxes of $\mathrm{N}_{2} \mathrm{O}$ representative for emissions from the Netherlands. The error bars represent the $\pm 1 \sigma$ uncertainties of the linear regression fits of the slopes. The value of the national inventories is indicated by the straight line. (b) Histogram of the $\mathrm{N}_{2} \mathrm{O}$ fluxes with a lognormal fit. Fit quality is excellent $(R=0.97)$. The arrows represent the values found using the lognormal approach (1) and the national inventory (2).

mal approach (see Fig. 7b) an annual emission was found for this period of $(9.2 \pm 0.3) \cdot 10^{-1} \mathrm{t} \mathrm{km}^{-2} \mathrm{a}^{-1}$. The average value of the inventories for the years 2006 and 2007 is (12.6 \pm 5.7$)$ $\cdot 10^{-1} \mathrm{t} \mathrm{km}^{-2} \mathrm{a}^{-1}$. Our results are therefore $28 \%$ lower. We find a median of $12.1 \cdot 10^{-1} \mathrm{t} \mathrm{km}^{-2} \mathrm{a}^{-1}$ and using the (inappropriate) Gaussian approach a monthly means based value of $(13.9 \pm 1.7) \cdot 10^{-1} \mathrm{t} \mathrm{km}^{-2} \mathrm{a}^{-1}$.

\subsection{Long range events}

As explained in Sect. 3.2 the long-range dataset contains a mixture of data which are not so clearly defined as the shortrange events. In order to get an idea of the origin of the emissions the mixing ratios of $\mathrm{CH}_{4}$ (Fig. 8a) and $\mathrm{N}_{2} \mathrm{O}$ (Fig. 8b) were plotted against the wind direction and wind speed for the period of May 2006 to April 2009. In Fig. 8a a clear distinction can be made between continental and oceanic air masses. The higher mixing ratios almost perfectly follow the coastal line-visualizing the mainland. The highest mixing ratios of $\mathrm{CH}_{4}$ are observed mostly between $120^{\circ}$ and $240^{\circ}$ at wind speeds between 5 and $15 \mathrm{~m} \mathrm{~s}^{-1}$. Possible sources

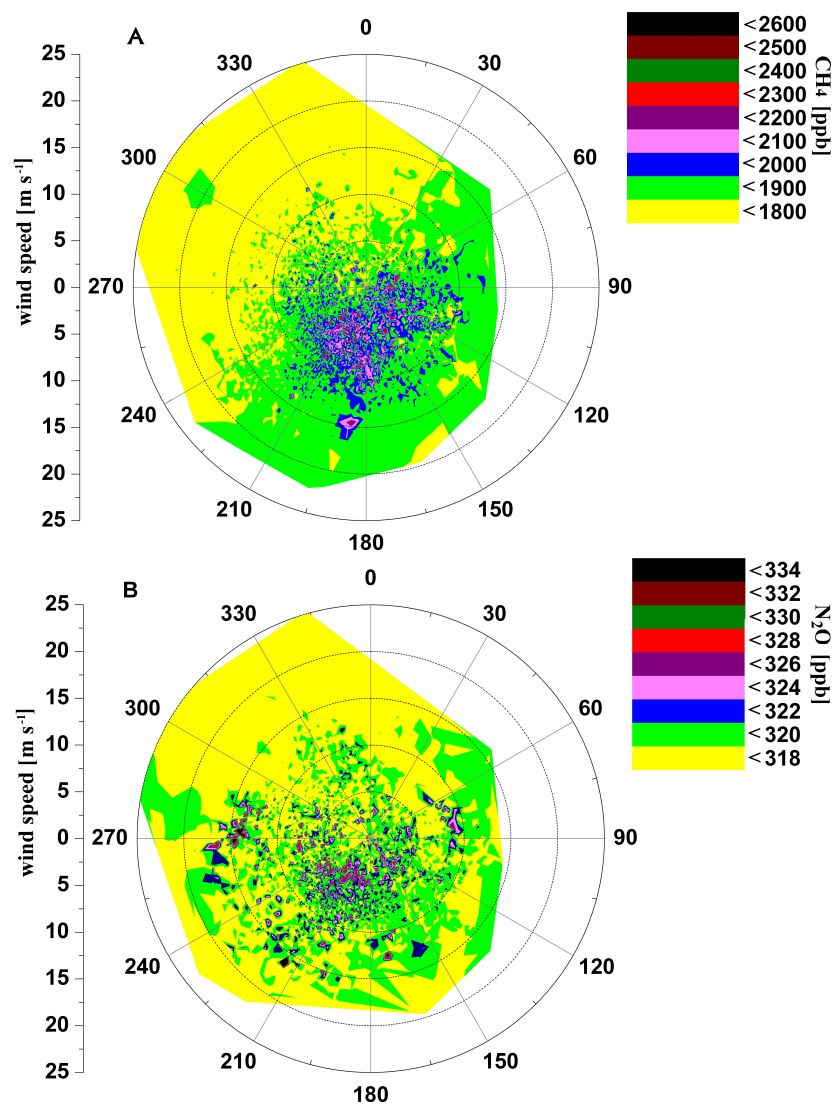

Fig. 8. (a) Concentration footprint of $\mathrm{CH}_{4}$ for the period of May 2006 to May 2008. Only long-range data were used. The highest mixing ratios are observed between $120^{\circ}$ and $240^{\circ}$ at wind speeds between 5 and $15 \mathrm{~m} \mathrm{~s}^{-1}$. The coastal line of N.W. Europe is clearly visible. (b) Similar to (a) but for $\mathrm{N}_{2} \mathrm{O}$. The highest mixing ratios are observed at about the same wind direction as for $\mathrm{CH}_{4}$ but at lower wind speeds (around $5 \mathrm{~m} \mathrm{~s}^{-1}$ ).

of these emissions could be the German Ruhr basin $\left(150^{\circ}-\right.$ $170^{\circ}$ ) at approx. $200 \mathrm{~km}$ distance from our station and the highly populated areas in the south of The Netherlands (approx. $200 \mathrm{~km}$ ) and Belgium (approx. $300 \mathrm{~km}$ ). In Fig. $8 \mathrm{~b}$ the same exercise is performed for $\mathrm{N}_{2} \mathrm{O}$. The highest mixing ratios are observed at about the same wind direction as for $\mathrm{CH}_{4}$ but at lower wind speeds (around $5 \mathrm{~m} \mathrm{~s}^{-1}$ ). Also a source of $\mathrm{N}_{2} \mathrm{O}$ is present at $270^{\circ}$, observed at wind speeds of about $15 \mathrm{~m} \mathrm{~s}^{-1}$. The relatively high mixing ratios, namely for $\mathrm{N}_{2} \mathrm{O}$, observed at relative low wind speeds suggest that the observations are still influenced by emissions from The Netherlands.

In order to estimate fluxes from the long range dataset we excluded the marine sector and binned the data into monthly datasets from which the regression slopes and consequently the fluxes were determined. This implies that the lowest mixing ratio in the month is used as a baseline. Although it is virtually impossible to estimate an exact 

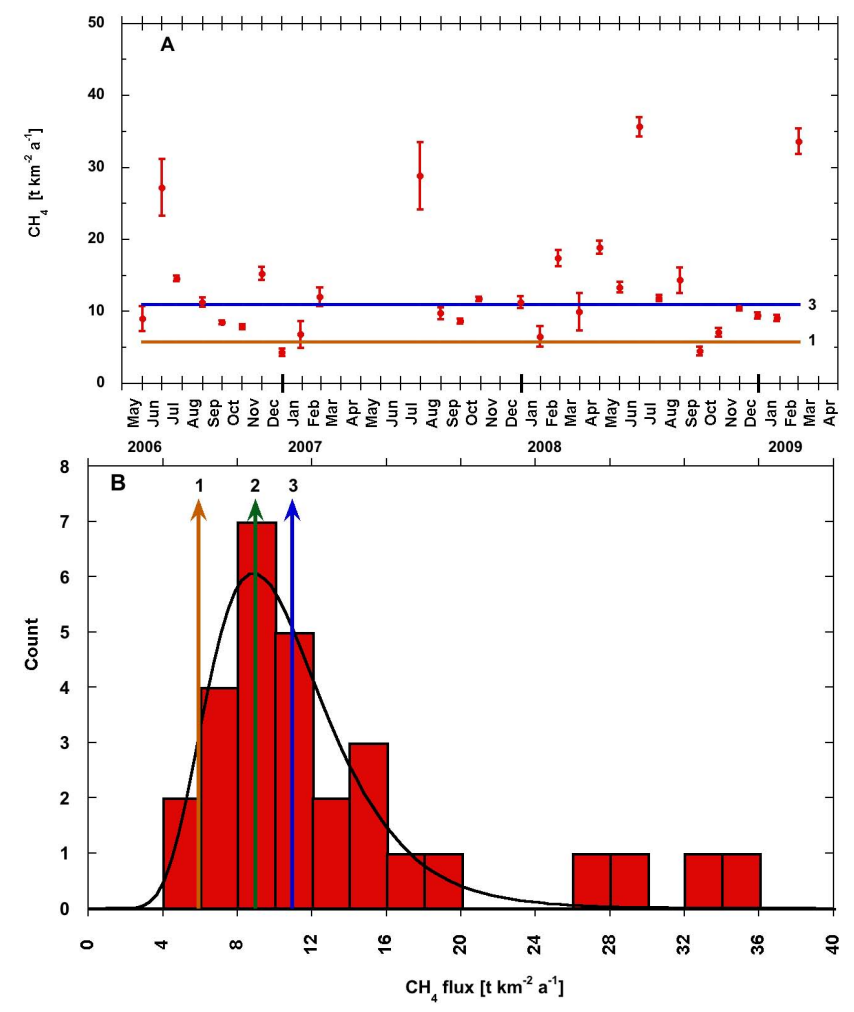

Fig. 9. (a) Monthly averaged fluxes of $\mathrm{CH}_{4}$ for the long-range dataset. The error bars represent the errors of the regressions fits of the individual slopes. The lines indicate the inventories of Germany (1) and Belgium (3). (b) Histogram of the long-range $\mathrm{CH}_{4}$ fluxes with a lognormal fit. Fit quality is very good $(R=0.94)$. The arrows represent the values found using the lognormal approach (2) and the national inventories of Germany (1) and Belgium (3).

${ }^{222} \mathrm{Rn}$ decay correction we corrected our fluxes for a $33 \%$ loss, based on a transit time of 3 days. This is an educated guess based on observations of multiple-day events of ${ }^{222} \mathrm{Rn}$. We decided to not apply a regression coefficient filter on the long-range dataset since, in contrast to the short-range fluxes which were more or less attributable to individual sources or source areas, these monthly fluxes include mixing ratios from many different sources. Figure 9a shows the monthly averaged fluxes of $\mathrm{CH}_{4}$ for the long-range dataset. Similar to our approach to the shortrange fluxes we used a lognormal regression fit to estimate an annual emission rate, see Fig. $9 \mathrm{~b}$. With this method we find annual $\mathrm{CH}_{4}$ emissions of $(8.9 \pm 0.3) \mathrm{tkm}^{-2} \mathrm{a}^{-1}$. The median of the monthly averaged fluxes is $11.3 \mathrm{t} \mathrm{km}^{-2} \mathrm{a}^{-1}$ and the mean is $(13.4 \pm 1.5) \mathrm{t} \mathrm{km}^{-2} \mathrm{a}^{-1}$. Figure 10a shows the monthly averaged fluxes of $\mathrm{N}_{2} \mathrm{O}$ for the same period and these values are fitted with a lognormal regression fit, as shown in Fig. 10b. For $\mathrm{N}_{2} \mathrm{O}$ we find an annual emission of (4.2 \pm 0.3$) \cdot 10^{-1} \mathrm{t} \mathrm{km}^{-2} \mathrm{a}^{-1}$ using the lognormal approach. The median is $5.7 \cdot 10^{-1} \mathrm{t} \mathrm{km}^{-2} \mathrm{a}^{-1}$ and the mean is (6.5 \pm 0.6$) \cdot 10^{-1} \mathrm{t} \mathrm{km}^{-2} \mathrm{a}^{-1}$.

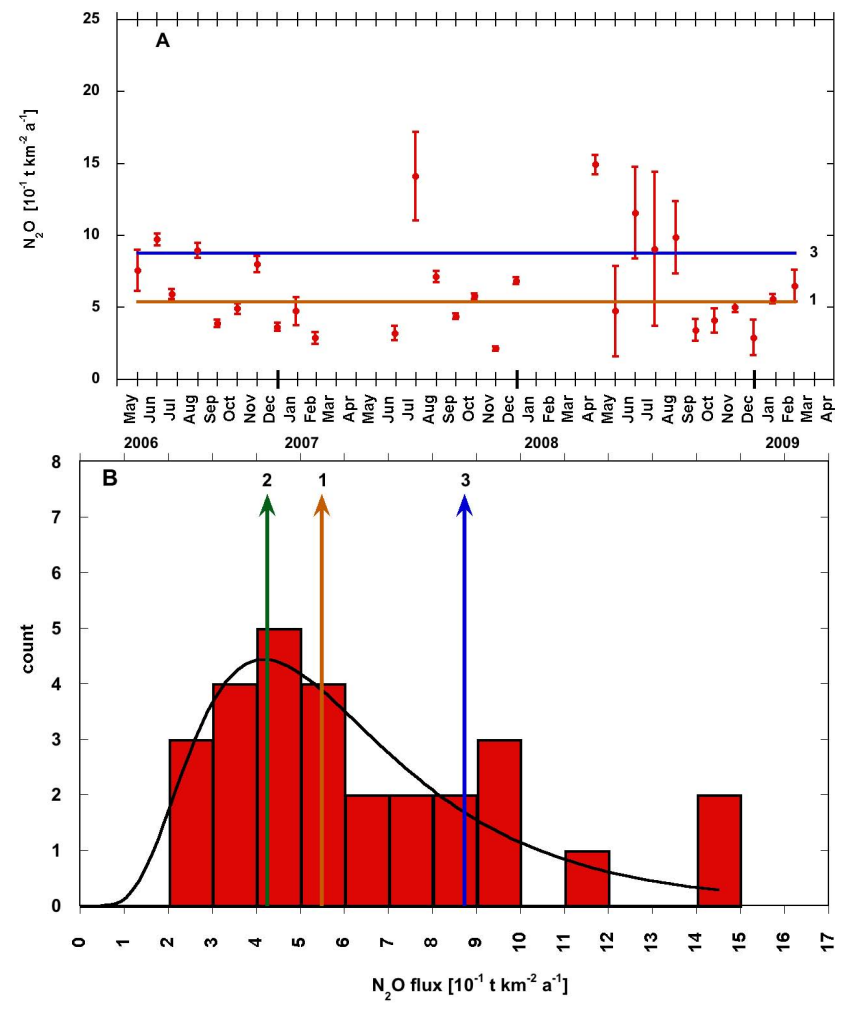

Fig. 10. (a) Monthly averaged fluxes of $\mathrm{N}_{2} \mathrm{O}$ for the long-range dataset. The error bars represent the errors of the regressions fits of the individual slopes. The lines indicate the inventories of Germany (1) and Belgium (3). (b) Histogram of the long-range $\mathrm{N}_{2} \mathrm{O}$ fluxes with a lognormal fit. Fit quality is very good $(R=0.96)$. The arrows represent the values found using the lognormal approach (1) and the national inventories of Germany (2) and Belgium (3).

\subsection{Uncertainty of the results}

The uncertainties given in Sect. 4.1 and 4.2 are only the uncertainties of the lognormal fit and are not representative for the combined uncertainty in the estimates of the annual fluxes. The combined uncertainty is determined by the accuracy and precision of our measurements, the uncertainties in the individual regression slopes and mostly by the uncertainty in the value of the assumed (average) ${ }^{222} \mathrm{Rn}$ soil emission rate.

The smallest uncertainties lie in the measurements of the atmospheric mixing ratios of $\mathrm{CH}_{4}, \mathrm{~N}_{2} \mathrm{O}$ and ${ }^{222} \mathrm{Rn}$. $\mathrm{CH}_{4}$ and $\mathrm{N}_{2} \mathrm{O}$ are measured with a gas chromatograph with an estimated combined uncertainty of about $0.8 \mathrm{ppb}$ and $0.3 \mathrm{ppb}$ respectively. The uncertainty of the ambient ${ }^{222} \mathrm{Rn}$ measurements is related to the amount of counts (per event) and the uncertainty in the ${ }^{222} \mathrm{Rn}$ source which is used to calibrate the device. The combined uncertainty of our ${ }^{222} \mathrm{Rn}$ measurements was about $5 \%$. 
The uncertainties in the linear regression fits of the slopes of $\mathrm{CH}_{4}$ and $\mathrm{N}_{2} \mathrm{O}$ vs. ${ }^{222} \mathrm{Rn}$ were typically $10 \%$. The main source of uncertainty concerning our final results lies in the assumption of the ${ }^{222} \mathrm{Rn}$ soil flux, which we assumed to be constant for the whole measurement period. However, although the production of ${ }^{222} \mathrm{Rn}$ in the soils is constant, its exhalation rate is also influenced by atmospheric pressure, soil temperature and soil humidity. This leads to a temporal variability of the net emissions which was estimated by Eckhardt (1990) to be in the order of $\pm 20 \%$. Furthermore, The Netherlands, although a very small country, has a large soil heterogeneity. Differences between the coastal areas and the southern inland part of the country can lead to differences in the ${ }^{222} \mathrm{Rn}$ soil flux up to $30 \%$. Taking these factors into account we estimate that our measurement-based annual emissions have a combined uncertainty of about $\pm 35 \%$. In Table 1 also the final results are given including an uncertainty of $\pm 35 \%$.

\section{Discussion and conclusions}

The method we used in this study is a valuable independent verification of the statistical approach usually applied for reporting the national emissions. The method is purely observation-based and almost independent of numerical models. There are, however, several uncertainties involved in this method. Although the calculated emissions are based on ambient measurements, we still rely on models to allocate the emissions to their source areas. In this study for example, we used a back trajectory model to filter out any events from our short-range dataset which appeared to be influenced (also) by emissions from abroad.

For the linear regression fits of the individual events we used a threshold of $R>=0.7$. The results would be lower by $5 \%$ with $R>=0.6$ and higher by $8 \%$ with $R>=0.8$. The positive correlation could be caused by the fact that air masses containing emissions from very nearby are probably less disturbed and thus give a high correlation between ${ }^{222} \mathrm{Rn}$ and $\mathrm{CH}_{4}$ or $\mathrm{N}_{2} \mathrm{O}$. Furthermore, these local (point) sources could be overestimated as the soil close to the tower has a relative high moisture content and therefore a lower radon soil flux compared to the average value of The Netherlands. Using a high $R$ as a threshold value does therefore not necessary guarantee more reliable results (in terms of estimating national emissions).

The largest uncertainty lies in the translation of the mixing ratios of $\mathrm{CH}_{4}$ and $\mathrm{N}_{2} \mathrm{O}$ into their surface fluxes. In this study, a constant ${ }^{222} \mathrm{Rn}$ surface emission rate was assumed based on a newly available European ${ }^{222} \mathrm{Rn}$ soil emission map (Szegvary, 2007). In reality, the ${ }^{222} \mathrm{Rn}$ surface emission rate can be affected at very small time scales (i.e. hours or days) by for example rain or snow. Although this will proportionally affect the calculated fluxes, we assume that the total uncertainty in our annual estimates due to this temporal variability is minor. The spatial variation of the ${ }^{222} \mathrm{Rn}$ surface emission rate can be large, even for a small country as The Netherlands this amounts to about $\pm 30 \%$. Since the sources are not homogeneously distributed throughout the country this is also the potential uncertainty of the individual fluxes. The total uncertainty in the annual estimates due to the spatial variation of the ${ }^{222} \mathrm{Rn}$ surface emission is probably less. A systematic error is introduced in the fluxes and the annual estimates if the average ${ }^{222} \mathrm{Rn}$ surface emission rate is incorrect. Since the calculated surface emissions of $\mathrm{CH}_{4}$ and $\mathrm{N}_{2} \mathrm{O}$ are directly proportional to this applied ${ }^{222} \mathrm{Rn}$ surface emission rate, any offset in its assumed value will be included in the final results. On the other hand, should more reliable data on ${ }^{222} \mathrm{Rn}$ emissions become available, our values can be adjusted in a simple way.

The emissions which we classified as long-range data have additional factors of uncertainty because they consist of a mix of signals with different temporal and spatial resolution. It is therefore virtually impossible to estimate the ${ }^{222} \mathrm{Rn}$ soil emission rate or determine a proper ${ }^{222} \mathrm{Rn}$ decay correction. Basically, our long-range dataset can include all ${ }^{222} \mathrm{Rn}$ mixing ratios older than the short-range data. A systematic error in the fluxes of about a factor of 2 is therefore possible. Furthermore, it is also not possible to exclude emissions from The Netherlands from the long range dataset. A long range event containing emissions from Germany or Belgium surely also picks up emissions from The Netherlands as it passes the country on its way to our measurement station. Since the ${ }^{222} \mathrm{Rn}$ soil flux is almost 2 times lower in The Netherlands as compared to the neighbouring countries, Dutch emissions will be over-amplified by a factor of two when only applying non-Dutch soil emission rates. Consequently the absolute value of the annual flux of the long-range data will probably not be representative for the surface emissions of Germany and Belgium. Nevertheless, the method can still be valuable to assess long-term trends.

For The Netherlands, we found net emissions of: $15.2 \pm 5.3 \mathrm{t} \mathrm{km}^{-2} \mathrm{a}^{-1}$ for $\mathrm{CH}_{4}$ and $0.9 \pm 0.3 \mathrm{t} \mathrm{km}^{-2} \mathrm{a}^{-1}$ for $\mathrm{N}_{2} \mathrm{O}$. We compared our results to the national inventories (http://unfecc.int) as reported to the UNFCCC. Their uncertainties are estimated to be $18 \%$ for $\mathrm{CH}_{4}$ and $45 \%$ for $\mathrm{N}_{2} \mathrm{O}$ (Maas et al., 2008). We conclude that our estimates are only slightly lower than the inventory-based emissions (2006-2008 averages) of $18.3 \pm 3.3 \mathrm{t} \mathrm{km}^{-2} \mathrm{a}^{-1}$ for $\mathrm{CH}_{4}$, and $1.3 \pm 0.6 \mathrm{t} \mathrm{km}^{-2} \mathrm{a}^{-1}$ for $\mathrm{N}_{2} \mathrm{O}$ and well within the error margins of the inventories. Therefore, we further conclude that station Lutjewad is well suitable for the determination of the national emissions of $\mathrm{CH}_{4}$ and $\mathrm{N}_{2} \mathrm{O}$ and validation of the national inventories.

In a forthcoming paper, we will apply the same method to determine the fossil fuel $\mathrm{CO}_{2}$ emissions of The Netherlands, and discuss our ${ }^{222} \mathrm{Rn}$-based flux methodology further. 
Acknowledgements. This project has been co-funded by the Dutch national research programme Climate changes Spatial Planning (CcSP), project ME2 "Integrated observations and modeling of Greenhouse Gas budgets at the national level in The Netherlands", and by the EU-commission FP6- project CarboEurope-IP (contract nr. GOCE-CT-2003-505572).

The authors would also like to thank B. A. M. Kers, J. C. Roeloffzen, and J. K. Schut for technical assistance and I. T. Van der Laan-Luijkx, and A. T. Vermeulen for fruitful discussions.

Edited by: A. Hofzumahaus

\section{References}

Biraud, S., Ciais, P., Ramonet, M., Simmonds, P., Kazan, V., Monfray, P., O'Doherty, S., Spain, T. G., and Jennings, S. G.: European greenhouse gas emissions estimated from continuous atmospheric measurements and Radon 222 at Mace Head, Ireland, J. Geophys. Res.-Atmos., 105, 1351-1366, 2000.

Biraud, S., Ciais, P., Ramonet, M., Simmonds, P., Kazan, V., Monfray, P., O’Doherty, S., Spain, G., and Jennings, S. G.: Quantification of carbon dioxide, methane, nitrous oxide and chloroform emissions over Ireland from atmospheric observations at Mace Head, Tellus, 54, 41-60, 2002.

Draxler, R. R., and Rolph, G. D.: HYSPLIT (HYbrid SingleParticle Lagrangian Integrated Trajectory) Model access via NOAA ARL READY Website (http://www.ready.noaa.gov/ ready/hysplit4.html), NOAA Air Resources Laboratory, Silver Spring, MD, USA, 2003.

Eckhardt, K.: Messung des Radonflusses und seiner Abhängigkeit von der Bodenbeschaffenheit, Diplomarbeit, Univ. of Heidelberg, Heidelberg, Germany, 1990.

Forster, P., Ramaswamy, V., Artaxo, P., Berntsen, T., Betts, R., Fahey, D. W., Haywood, J., Lean, J., Lowe, D. C., Myhre, G., Nganga, J., Prinn, R., Raga, G., Schulz, M., and Van Dorland, R.: Changes in Atmospheric Constituents and in Radiative Forcing, in: Climate Change 2007: The Physical Science Basis. Contribution of Working Group I to the Fourth Assessment Report of the Intergovernmental Panel on Climate Change, edited by: Solomon, S., Qin, D., Manning, M., Chen, Z., Marquis, M., Averyt, K. B., Tignor, M., and Miller, H. L., Cambridge University Press, Cambridge, UK and New York, NY, USA, 2007.

Gaudry, A., Polian, G., Ardouin, B., and Lambert, G.: Radoncalibrated emissions of $\mathrm{CO}_{2}$ from South Africa, Tellus B, 42, 9-19, 1990.

Levin, I.: Atmospheric $\mathrm{CO}_{2}$, sources and sinks on the European continent (in German), Ph.D. Thesis, Univ. of Heidelberg, Heidelberg, Germany, 103 pp., 1984.

Levin, I.: Atmospheric $\mathrm{CO}_{2}$ in continental Europe - an alternative approach to clean air $\mathrm{CO}_{2}$ data, Tellus, 39B, 21-28, 1987.

Levin, I., Glatzel-Mattheier, H., Marik, T., Cuntz, M., Schmidt, M., and Worthy, D. E.: Verification of German methane emission inventories and their recent changes based on atmospheric observations, J. Geophys. Res.-Atmos., 104, 3447-3456, 1999.

Levy, P. E., Grelle, A., Lindroth, A., Molder, M., Jarvis, P. G., Kruijt, B., and Moncrieff, J. B.: Regional-scale $\mathrm{CO}_{2}$ fluxes over central Sweden by a boundary layer budget method, Agr. Forest Meteorol., 98-9, 169-180, 1999.
Maas, C. W. M. v. d., Coenen, P. W. H. G., Ruyssenaars, P. G., Vreuls, H. H. J., Brandes, L. J., Baas, K., Berghe, G. v. d., Born, G. J. v. d., Guis, B., Hoen, A., Molder, R., Nijdam, D. S., Olivier, J. G. J., Peek, C. J., and Schijndel, M. W. v.: Greenhouse gas emissions in the Netherlands 1990-2006, Netherlands Environmental Assesment Agency (MNP) National inventory report 2008, Report no. 500080009 Bilthoven, The Netherlands, 263 pp., 2008.

Messager, C., Schmidt, M., Ramonet, M., Bousquet, P., Simmonds, P., Manning, A., Kazan, V., Spain, G., Jennings, S. G., and Ciais, P.: Ten years of $\mathrm{CO}_{2}, \mathrm{CH}_{4}, \mathrm{CO}$ and $\mathrm{N}_{2} \mathrm{O}$ fluxes over Western Europe inferred from atmospheric measurements at Mace Head, Ireland, Atmos. Chem. Phys. Discuss., 8, 1191-1237, 2008, http://www.atmos-chem-phys-discuss.net/8/1191/2008/.

Neubert, R. E. M., Spijkervet, L. L., Schut, J. K., Been, H. A., and Meijer, H. A. J.: A Computer-Controlled Continuous Air Drying and Flask Sampling System, J. Atmos. Ocean. Tech., 21, 651659, 2004.

Rohrer, F., Brüning, D., Grobler, E. S., Weber, M., Ehhalt, D. H., Neubert, R., Schüßler, W., and Levin, I.: Mixing Ratios and Photostationary State of $\mathrm{NO}$ and $\mathrm{NO}_{2}$ Observed during the POPCORN Field Campaign at a Rural Site in Germany, J. Atmos. Chem., 31, 119-137, 1998.

Schmidt, M., Graul, R., Sartorius, H., and Levin, I.: Carbon dioxide and methane in continental Europe: a climatology, and ${ }^{222}$ Radon-based emission estimates, Tellus B, 48, 457-473, 1996.

Schmidt, M., Glatzel-Mattheier, H., Sartorius, H., Worthy, D. E., and Levin, I.: Western European $\mathrm{N}_{2} \mathrm{O}$ emissions: A top-down approach based on atmospheric observations, J. Geophys. Res., 106, 5507-5516, 2001.

Schmidt, M., Graul, R., Sartorius, H., and Levin, L.: The Schauinsland $\mathrm{CO}_{2}$ record: 30 years of continental observations and their implications for the variability of the European $\mathrm{CO}_{2}$ budget, $\mathrm{J}$. Geophys. Res.-Atmos., 108, 4619-4626, 2003.

Schrimpf, W., Lienaerts, K., Müller, K. P., Rudolph, J., Neubert, R., Schüssler, W., and Levin, I.: Dry deposition of peroxyacetyl nitrate (PAN): Determination of its deposition velocity at night from measurements of the atmospheric PAN and (222)Radon concentration gradient, Geophys. Res. Lett., 23, 3599-3602, 1996.

Szegvary, T.: European ${ }^{222} \mathrm{Rn}$ flux map for atmospheric tracer applications, PhD thesis, Institute of Environmental Geosciences, University of Basel, Basel, Switzerland, 2007.

Thom, M., Bösinger, R., Schmidt, M., and Levin, I.: The Regional Budget of Atmospheric Methane of a Highly Populated Area, Chemosphere, 26, 143-160, 1993.

Van der Laan, S., Neubert, R. E. M., and Meijer, H. A. J.: A single gas chromatograph for atmospheric mixing ratio measurements of $\mathrm{CO}_{2}, \mathrm{CH}_{4}, \mathrm{~N}_{2} \mathrm{O}, \mathrm{SF}_{6}$ and $\mathrm{CO}$, Atmos. Meas. Tech., 2, 549559, 2009, http://www.atmos-meas-tech.net/2/549/2009/.

Whittlestone, S., and Zahorowski, W.: Baseline radon detectors for shipboard use: Development and deployment in the First Aerosol Characterization Experiment (ACE 1), J. Geophys. Res., 103(D13), 16743-16751, 1998.

Wilson, S. R., Dick, A. L., Fraser, P. J., and Whittlestone, S.: Nitrous oxide flux estimates for south-eastern Australia, J. Atmos. Chem., 26, 169-188, 1997. 